\title{
O Papel do Diretor Escolar na Implantação de uma Cultura Educacional Inclusiva
}

The School Principal's Role into the Accomplishment of an Inclusive Educational Culture

El Papel del Director Escolar en la Implantación de una Cultura Escolar Inclusiva

Claudia Lopes da Silva \& Maria Isabel da Silva Leme

Universidade de São Paulo

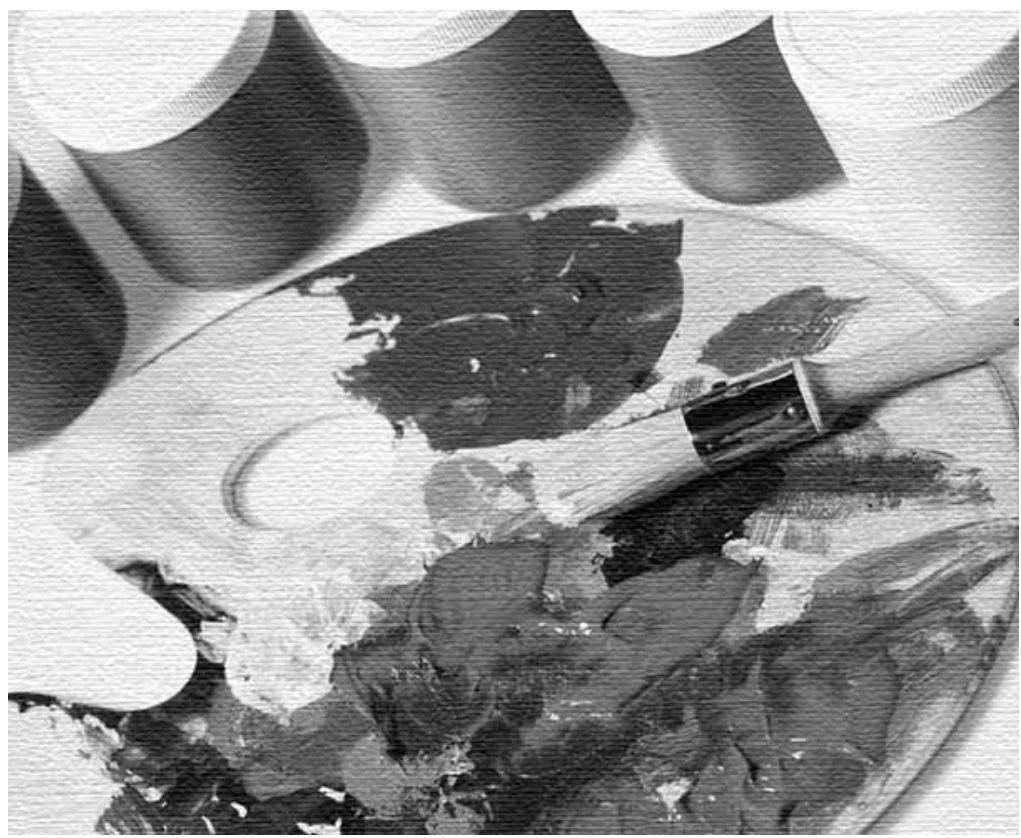


Resumo: Investiga-se aqui o papel do diretor escolar na constituição de uma cultura escolar inclusiva, tendo como referencial teórico a Psicologia histórico-cultural de Vigotski. Busca-se estabelecer uma relação entre a democratização da escola e a implantação de uma cultura escolar inclusiva através da atuação do diretor escolar. Como hipótese, considerou-se que o diretor influencia de maneira decisiva a forma como se constitui a cultura escolar, facilitando ou dificultando a efetivação da inclusão escolar. Os conceitos de cultura escolar, educação inclusiva e ambiente inclusivo foram examinados de forma a estabelecer a importância do contexto da escola na inclusão escolar de alunos com deficiência. Realizou-se um estudo de caso, tendo sido colhidos dados por meio de análise documental e realizada entrevista com uma diretora escolar. Foi utilizado como método a análise de conteúdo de Bardin. Como resultado, concluiu-se que a democratização da gestão e a educação inclusiva se encontram estreitamente relacionadas, o que sugere que uma escola inclusiva é, antes de tudo, uma escola democrática.

Palavras-chave: Inclusão escolar. Administração educacional. Ambiente escolar. Psicologia histórico-cultural.

Abstract: The present work investigates the school principal's role in the construction of an inclusive schooling culture. The approach is theoretically based on Vigotski's cultural-historical psychology. The research aims to establish relationships between the school democratization process and the implantation of an inclusive school culture, through the school principal's action. It was considered the hypothesis that the principal exerts decisive influence on the way the school culture is constituted, what can facilitate or not the school inclusion. The research includes the concepts of school culture, inclusive education and inclusive environment as a way of establishing the school's context relevance to the school inclusion of students with special needs. The research was conducted as a case study, and procedures as the researcher's report, paper analysis and an interview with the principal of the school were used. Bardin's method of content analysis was employed to analyze the data collected. Results favored the conclusion that the managing democratization process and the inclusive education are related in a very important way, suggesting that an inclusive school is, above all, a democratic school.

Keywords: School inclusion. Educational management. School environment. Cultural-historical psychology.

Resumen: Se investiga aquí el papel del director escolar en la constitución de una cultura escolar inclusiva, teniendo como referencial teorético la Psicología histórico-cultural de Vigotski. Se busca establecer una relación entre la democratización de la escuela y la implantación de una cultura escolar inclusiva a través de la actuación del director escolar. Como hipótesis, se consideró que el director influencia de manera decisiva la forma como se constituye la cultura escolar, facilitando o dificultando la efectuación de la inclusión escolar. Los conceptos de cultura escolar, educación inclusiva y ambiente inclusivo fueron examinados de forma que establezca la importancia del contexto de la escuela en la inclusión escolar de alumnos con deficiencia. Se realizó un estudio de caso, habiendo sido cogidos datos por medio de análisis documental y realizada entrevista con una directora escolar. Fue utilizado como método el análisis de contenido de Bardin. Como resultado, se concluyó que la democratización de la gestión y la educación inclusiva se encuentran estrechamente relacionadas, lo que sugiere que una escuela inclusiva es, antes de todo, una escuela democrática.

Palabras clave: Inclusión social. Administración educacional. Ambiente escolar. Psicología histórico-cultural.

Este trabalho focaliza o papel do diretor escolar na formação de uma cultura escolar inclusiva. A hipótese sustentada é de que sua posição de autoridade e liderança, e principalmente seu papel como articulador do projeto pedagógico, são fundamentais no processo de inclusão escolar de alunos com necessidades educacionais especiais, notadamente aqueles com deficiências. Essas reflexões serão fundamentadas teoricamente na Psicologia histórico-cultural de Vigotski, o que se justifica pela importância conferida por esse autor ao contexto escolar na aprendizagem e no desenvolvimento.
Para Vigotski, a cultura é uma instância mediadora entre as pessoas e o mundo em que vivem bem como entre as pessoas e elas mesmas, e possui tanto a função de determinante quanto de produto das relações humanas. O desenvolvimento filogenético e ontogenético do ser humano é mediado pela cultura, e a impregnação social e cultural do psiquismo possibilitou a diferenciação humana ao longo da História. A humanidade tornou-se o que é porque cria, assimila e reconstrói a cultura, que é formada por elementos materiais e simbólicos. O desenvolvimento da criança se encontra 
inevitavelmente vinculado à incorporação mais ou menos criativa da cultura de sua comunidade (Pérez Gómez, 1998).

Brandão (1983) define a relação da cultura com a educação como um processo de transformação daquilo que já foi anteriormente transformado por meio do trabalho e da consciência. O processo de socialização do indivíduo na sua cultura é um processo de ensino e de aprendizagem que ocorre implicitamente, sendo anterior ao surgimento do ensino formal. Na medida em que as organizações sociais se tornam mais complexas, as formas e os processos envolvidos na transmissão do saber são vistos como um problema a ser pensado, que dá origem à educação formal.

A teoria das organizações diferencia cultura organizacional de estrutura organizacional (Nóvoa, 1995). Nessa perspectiva, a escola como organização social pode ser vista como possuidora de uma cultura própria, na qual o pesquisador focaliza sua atenção para compreender o ato educativo que ocorre nesse contexto. A cultura escolar pode ainda ser caracterizada pelo chamado currículo oculto, ou seja, pelas diretrizes tácitas que atuam de modo importante no funcionamento da escola e nas práticas dos seus profissionais. Tais diretrizes afetam a aprendizagem dos alunos e o trabalho dos professores, configurando os valores e os significados vivenciados na própria escola. O currículo está "oculto", porque ele não é prescrito, embora se constitua em importante fator de aprendizagem.

Não se deve esquecer também que a escola está inserida em um contexto sociocultural e político mais amplo, cuja influência é determinante na sua organização, daí a importância de se considerar os valores e as interpretações das pessoas em relação aos objetivos e propósitos sociais da organização escolar dentro da realidade sociocultural e política (Libâneo, 2001). A escola, portanto, não divulga simplesmente o conhecimento acumulado pela humanidade, mas o seu recorte, contextualizado social e historicamente nas práticas de formação do indivíduo, de socialização do conhecimento e de reprodução social (Silva Jr. \& Ferretti, 2004).

Decorre daí que a principal questão não é "investigar como a criança se socializa, mas como a sociedade socializa a criança" (Miranda, 2004, p. 131). Por meio de processos de socialização vividos na escola, a criança internaliza valores e comportamentos da sua cultura, sendo fundamental compreender como se dá esse processo. A escola pode ser vista, portanto, como uma organização social dotada de uma cultura própria, e, ao mesmo tempo, como parte de uma cultura mais ampla, que reflete em suas ações os condicionantes e contradições ali presentes.

Fica patente a importância que o processo de escolarização exerce na vida da criança, por ser a escola o espaço de socialização mais legitimado na sociedade atual, onde se recria um conhecimento específico, diferente da educação informal ou familiar. Excluir a criança com deficiência da escola significa, portanto, negar-lhe o acesso a essa forma de aquisição cultural específica e fundamental em uma sociedade em que a educação escolar é altamente valorizada. "O fato de o indivíduo não ter acesso à escola significa um impedimento da apropriação do saber sistematizado, de instrumentos de atuação no meio social e de condições para a construção de novos conhecimentos" (Rego, 2002, p. 48).

Nessa perspectiva, a escola desempenha papel importante não só na aquisição sistematizada de conhecimentos mas também no desenvolvimento das funções psicológicas superiores, isso porque as atividades educativas na escola, diferentemente do cotidiano extra-escolar, são sistemáticas, têm uma intencionalidade deliberada e um compromisso explícito em tornar 
${ }^{1}$ Neste trabalho, emprega-se a grafia Vigotski, por ser a utilizada nas traduções mais recentes em português da obra do autor a partir do original em russo. As diversas publicações, contudo, utilizam diferentes grafias que, ao serem aqui referidas, serão preservadas em sua apresentação original, o que impedirá a

padronização do nome do autor nas citações feitas. Para maiores detalhes sobre essa questão, sugere-se a consulta de Duarte (2001), nota de rodapé das páginas 2-3. acessível o conhecimento formalmente organizado. Em tal contexto, os estudantes são desafiados a entender as bases dos sistemas de concepções científicas, a realizar abstrações e generalizações mais amplas acerca da realidade e, ainda, a tomar consciência de seus próprios processos mentais (metacognição), modificando a relação cognitiva com o mundo.

\section{A contribuição de Vigotski para a compreensão da deficiência}

Pode-se destacar a ênfase dada pelo autor aos aspectos qualitativos em detrimento dos quantitativos envolvidos no estudo da deficiência. Para ele, o desenvolvimento de uma criança com deficiência não deveria ser relativizado no que se refere ao desenvolvimento normal como quantitativamente menor, mas sim, qualitativamente diferenciado (Vigotski, 1929/1997) ${ }^{1}$. Acreditava esse autor que a deficiência tivesse um papel duplo no desenvolvimento e na formação da personalidade da criança, pois se, por um lado, é uma limitação, por outro, justamente por isso, estimula um avanço intenso. Afirmava que toda deficiência cria os estímulos para uma compensação. Dessa forma, deve-se examinar o indivíduo com deficiência, e não a deficiência de forma isolada, a fim de compreender como esse processo de compensação ocorre.

Vigotski assegurava que a ação da deficiência é sempre secundária, pois a criança com deficiência não a sente diretamente, e sim, as dificuldades sociais decorrentes dessa ação. A compensação da deficiência criaria uma posição psicológica particular na criança, que afetaria seu desenvolvimento. O autor também destaca a finalidade social da compensação, pois esta faz com que a criança se adapte às condições oferecidas pelo ambiente, criado para um ser humano não-deficiente. Portanto, uma criança com deficiência não é necessariamente uma criança deficiente: o grau de sua deficiência e normalidade depende do resultado da compensação social.

Para Vigotski, é clara a importância do ambiente no desenvolvimento de toda criança, assumindo um papel ainda mais crucial no caso da criança com deficiência. A mediação do adulto, ou do contexto cultural, para o desenvolvimento da criança não é apenas desejável, mas fundamental. A criança irá desenvolver-se, segundo Vigotski, em função das suas experiências com o contexto social em que está inserida, já que é pela internalização dessas experiências sociais que o seu psiquismo se constitui. Daí decorre a afirmação do autor que o desenvolvimento incompleto das funções superiores na criança com deficiência se deve ao seu isolamento do contexto social (Vigotski, 1931/1997). Assim, por exemplo, uma criança com deficiência visual não terá acesso a determinados produtos culturais, como um livro, se não forem proporcionados recursos que possibilitem a ela o acesso a esse objeto, como a transcrição em braile. Proporcionados os recursos, a criança não estará mais isolada, e poderá participar mais amplamente da coletividade, interagindo com os outros de forma a incorporar elementos que ampliem suas possibilidades de desenvolvimento bem como contribuir para o desenvolvimento dos outros participantes da coletividade. Como a sociedade é planejada para pessoas sem deficiência, é preciso um cuidado redobrado para que a criança com deficiência não tenha suas possibilidades de desenvolvimento limitadas pela inadequação do contexto, o que é particularmente importante na escola, uma vez que é nesse ambiente que a criança experimentará atividades intencionalmente planejadas para o seu desenvolvimento.

Nesse sentido, Vigotski defendeu o ensino não segregado para crianças com deficiência, o que é coerente com sua visão do desenvolvimento humano impulsionado pelo ambiente social: “do ponto de vista psicológico, é sumamente 
importante não isolar essas crianças em grupos fechados especiais, mas exercitar o mais amplamente possível sua comunicação com os demais" (Vigotski, 2003). As maiores dificuldades apontadas pelo autor referemse aos aspectos práticos da organização escolar e pedagógica, visto que os benefícios para os alunos parecem evidentes. Vigotski considera essa integração benéfica mesmo para crianças com comprometimentos mais graves, alertando que ajustes ambientais não converterão qualquer comportamento anormal em normal, mas é a atitude mais pertinente em face dos conhecimentos disponíveis sobre essas patologias.

Vale lembrar que a deficiência não deve ser considerada um fenômeno em si, mas em relação ao contexto social que Ihe atribui maior ou menor desvantagem. O significado social da deficiência não pode ser atribuído a características inerentes à pessoa com deficiência, mas ao modo como estas são valorizadas em uma determinada cultura, que pode camuflar possíveis problemas no interior de um grupo ou organização, como localizar no indivíduo a deficiência e até a sua causa (Omote, 1994). O fenômeno da construção social da deficiência explica também a não-deficiência, construída por meio dos mesmos mecanismos. Assim, a cultura escolar, traduzida nos valores mantidos em cada escola a respeito da deficiência, terá uma importante influência na forma como esses alunos serão percebidos e tratados pelos diversos atores que a constituem.

\section{O ambiente educacional inclusivo}

A definição de educação inclusiva foi preconizada no documento Declaração de Salamanca sobre Princípios, Política e Prática na Área das Necessidades Educativas Especiais, produzido na conferência mundial realizada pela UNESCO, em 1994, na Espanha. Resumidamente, esse documento postula o direito fundamental de toda criança à educação, cujas características, interesses, habilidades e necessidades de aprendizagem são únicas. Afirma também que a diversidade deverá ser considerada nos sistemas e programas educacionais, o que significa que alunos com necessidades educacionais especiais devem ter acesso à escola regular. O princípio fundamental da escola inclusiva recomendado é o de que todas as crianças devem aprender juntas, sempre que possível, independentemente de quaisquer dificuldades ou diferenças que possam ter. As escolas devem, portanto, prover oportunidades curriculares que sejam apropriadas à criança com habilidades e interesses diferentes (UNESCO, 1994).

Tendo estabelecido a relação da educação escolar com o contexto social e cultural, bem como o conceito de educação inclusiva, cabe especificar como esta se traduz em termos de ambiente escolar, possibilitando a discussão do papel do diretor escolar na sua promoção.

Para que a inclusão de crianças com deficiência ocorra de modo sensível às necessidades de todos os envolvidos no processo educativo, é necessário um ambiente que considere as relações estabelecidas entre as pessoas, e não apenas as questões estruturais. Logicamente, pensar em um ambiente inclusivo conduz à idéia de acessibilidade arquitetônica, mas não é essa a tônica, e sim, as relações estabelecidas na escola. É interessante destacar também que o ambiente inclusivo independe da presença de crianças com deficiência, sendo antes de tudo um espaço onde se privilegiam as relações humanas. A implantação de tal ambiente demanda mudança da cultura institucional, uma das tarefas mais profundas e difíceis que uma organização pode enfrentar. Cada escola é um caso único de cultura institucional, fruto de um processo histórico, a ser repensado caso se almeje mudança (Sekkel, 2003).

Conclui-se, assim, que a constituição de um ambiente propício à inclusão escolar depende 
de uma construção coletiva, na qual o diretor escolar exercerá um papel decisivo. Portanto, é preciso conhecer melhor o papel do diretor/ gestor dentro da organização escolar.

A direção escolar é um dos processos da gestão de uma organização escolar, concretizada na tomada de decisões sobre a organização e a coordenação dos trabalhos. O nível de participação dada ao coletivo define o estilo de gestão. A gestão democrática procura atingir metas e cumprir responsabilidades decididas coletiva e cooperativamente, visando à melhoria do processo ensino-aprendizagem. Assim, os objetivos da escola são claros e podem ser assumidos por todos os profissionais envolvidos, principalmente no que se refere à tarefa educativa da instituição (Libâneo, 2001). O mesmo se aplica aos alunos, pois a gestão democrática não se limita ao acesso ao conhecimento artístico e científico humano, mas inclui também o desenvolvimento de valores democráticos, por meio de uma gestão cooperativa e solidária, favorecendo a ética e a liberdade, e não restrita a momentos pontuais (Paro, 2001).

Essa não é tarefa fácil, pois, em uma sociedade capitalista, o diretor escolar enfrenta contradições. Além de exercer a função de educador, que dá ênfase aos objetivos educacionais da escola, deve administrá-la de acordo com as orientações do sistema de ensino, que são freqüentemente burocráticas e alheias ao nível pedagógico. O diretor está ainda submetido a uma dupla pressão: o atendimento a reivindicações da comunidade escolar e a obediência ao sistema. Cabe a ele estar atento às relações de poder presentes no cotidiano escolar, buscando o que é legítimo, enquanto construção articulada entre os diferentes atores, sem o que arrisca a própria sobrevivência institucional, indispensável na coordenação das diferentes ações, recursos e esforços de todos os envolvidos (Vale, 1995).

Indubitavelmente, o diretor é uma figura essencial para a implantação e o bom desenvolvimento de qualquer inovação pedagógica, pois é ele que permite a abertura de novos espaços necessários à transformação do cotidiano escolar (Lima, 1993). A flexibilidade do diretor e a legitimidade atribuída por ele a posições contrárias à sua são condições para a abertura da escola (Almeida, 2003).

Entretanto, é importante lembrar que a cultura escolar pode frustrar esse processo, camuflando a recusa com uma aceitação aparente da transformação da prática. Nesse sentido, um dos papéis importantes da direção de uma escola é o de gerir através do exemplo, buscando mudar a cultura escolar por ações concretas, e não somente através de argumentos. Evidenciar para o grupo que o diretor pratica as ações recomendadas mostra que outros valores são possíveis, e que sua atuação não se restringe ao discurso (Glatter, 1995). Portanto, um ambiente inclusivo na escola depende de o diretor fortalecer a mentalidade de que a escola é de todas as crianças, proporcionando um modelo para os professores, bem como de incentivar aqueles que buscam práticas educacionais inclusivas. Cabe ainda ao diretor apoiar o professor que empreende ações para mudar, sem deixar de respeitar o ritmo pessoal de cada um na incorporação de uma atitude inclusiva. $\mathrm{O}$ diretor deve ser capaz de discernir o que a equipe como um todo e o que cada um necessita para se desenvolver (Sage, 1999).

Não se pode pretender, contudo, que a mudança da cultura escolar não seja afetada pelo sistema a que a escola pertence. Para tanto, os sistemas devem não só deixar clara essa mudança em termos de princípios, mas principalmente adotar ações coerentes com a inclusão escolar como fundamento (Sage, 1999). Em pesquisa destinada a levantar concepções de professores e diretores sobre educação inclusiva, Sant'Ana (2004) verificou que a presença de uma equipe que dê suporte aos agentes educacionais é mais lembrada por professores que diretores, ao passo 
Segundo

Stake (2000),

"um estudo

de caso é ao

mesmo tempo

o processo de

investigação

sobre o caso e

o produto dessa

investigação" (p.

436). Partindo

da classificação

proposta por esse

autor, o estudo

de caso em

questão seria do

tipo instrumental,

ou seja, o

exame de um

caso particular,

cujo objetivo é

esclarecer uma

questão. que os últimos favorecem mais a formação continuada. Para a autora, tal dado indica a necessidade dos professores de receber orientação e apoio para lidar com alunos com necessidades educacionais especiais, opinião corroborada por Prieto (2002).

Ao pesquisar o papel da gestão escolar na construção de uma escola inclusiva, Tezani (2004) encontrou uma relação expressiva entre a postura assumida pela gestão escolar e a influência na prática pedagógica cotidiana, ressaltando que o envolvimento dos pais e o comprometimento dos professores são fatores determinantes na construção da escola inclusiva.

\section{O estudo de caso de uma diretora}

Esta pesquisa, de caráter qualitativo em função de seu objeto, foi realizada como um estudo de caso sobre o papel do diretor na formação de uma cultura escolar inclusiva. Segundo Stake (2000), "um estudo de caso é ao mesmo tempo o processo de investigação sobre o caso e o produto dessa investigação" (p. 436). Partindo da classificação proposta por esse autor, o estudo de caso em questão seria do tipo instrumental, ou seja, o exame de um caso particular, cujo objetivo é esclarecer uma questão.

Um estudo de caso qualitativo exige ainda do pesquisador um grande investimento de tempo de pesquisa no local, a fim de entrar em contato pessoal com as atividades relacionadas ao caso bem como de refletir e revisar sua interpretação sobre o que observa (Stake, 2000). Cabe esclarecer, a esse respeito, que a primeira autora já atuava, dois anos antes desta pesquisa, como psicóloga em uma equipe multidisciplinar de orientação técnica na escola estudada. Tal relação profissional com a escola não caracteriza uma pesquisa etnográfica, em que a relação do pesquisador com a instituição é direcionada segundo o objetivo desta última. Contudo, a convivência e uma reflexão extensa sobre as relações ali estabelecidas, ainda que a partir de um outro lócus, garantem o necessário para as condições especificadas acima. O material reunido durante esse tempo de trabalho foi tomado como um elemento de pesquisa, o que contribuiu para a reflexão do papel do diretor nessa cultura escolar específica.

A equipe multidisciplinar de orientação técnica da secretaria de educação do Município onde o estudo ocorreu é composta por psicólogos escolares, fonoaudiólogos, pedagogos, assistentes sociais e terapeutas ocupacionais. As principais atividades dessa equipe referem-se a ações de formação e orientação escolar. Os psicólogos participantes buscam privilegiar um trabalho de formação da equipe gestora, composta por diretor, vice-diretor e professor coordenador, o que não significa que não haja uma demanda das equipes escolares por uma discussão sobre questões individuais relativas aos alunos.

Com o objetivo de contextualizar a escola pesquisada histórica e socialmente, foi realizada ainda uma pesquisa documental em fontes oficiais e públicas, que definem ações para a rede municipal de ensino e para a escola em questão, como, por exemplo, o Plano Municipal de Educação e a proposta curricular do Município. A pesquisa buscou identificar como as atribuições do diretor de escola são definidas e como são tratados os temas educação inclusiva e gestão democrática.

De forma geral, pode-se observar, na análise dos documentos, uma preocupação do Município com a educação inclusiva, tanto implícita como explicitamente, por meio de proposições objetivas. Observou-se ainda, nesta análise, uma progressiva transferência de responsabilidades, inicialmente centradas na educação especial, para as áreas de ensino regular. A preocupação inicial com diagnóstico clínico e encaminhamento é paulatinamente dividida com as escolas, por meio de orientação de encaminhamentos 
baseados em indicadores pedagógicos e pareceres das equipes técnicas. Também são aumentados gradualmente os recursos destinados à implantação da educação inclusiva, acessibilidade e tecnologia assistiva $^{2}$, enunciados nas metas estudadas nos documentos oficiais. A preocupação com a articulação entre os envolvidos também é constante, bem como a preocupação com a formação dos profissionais.

\section{Caracterização e histórico da instituição}

A escola em questão fica em um Município da Grande São Paulo. Foi inaugurada em 1985 como escola estadual, sendo municipalizada em 2004. O prédio apresenta acessibilidade arquitetônica deficitária, porém as classes com alunos com maior dificuldade de movimentação são geralmente colocadas no nível térreo. A escola localiza-se em um bairro periférico. A maior parte das moradias é de alvenaria, mas muitas resultam de ocupações, como favelas urbanizadas. Na época do estudo, funcionavam na escola 33 classes de ensino fundamental, organizadas em primeiro e segundo ciclo (equivalente a $1^{\underline{a}}$ à $4^{\underline{a}}$ serie) nos períodos matutino e vespertino, que atendiam cerca de 900 alunos. Trabalhavam na escola 33 professores, sendo 16 efetivos da rede municipal e 17 conveniados da rede estadual. A escola contava ainda com 4 professores substitutos e 5 estagiários. Três turmas de apoio pedagógico, formadas por alunos que haviam sido avaliados como tendo dificuldades de aprendizagem, funcionavam no período contrário ao das aulas regulares, e, à noite, duas turmas de educação de jovens e adultos. A escola tinha dois HTPC (horários de trabalho pedagógico coletivo), parte da carga horária de trabalho dos professores.

No início do estudo, em 2004, a antiga diretora do Estado estava se desligando da escola, por motivo de aposentadoria. Foi substituída por uma diretora não efetiva, porém contratada do Município, sendo depois sucedida por M., que participou do estudo.

Até 2004, não havia na escola alunos com deficiências mais expressivas. Alguns alunos com deficiência auditiva eram atendidos em sala de recursos. As principais questões trazidas à psicóloga em relação aos alunos eram indisciplina e questões de aprendizagem, com alguns índices altos de retenção ao final dos dois ciclos.

O primeiro aluno com deficiência mais significativa recebido pela escola foi G., com síndrome de Down, na gestão da primeira diretora do Município. Apesar de ter 10 anos, G. nunca havia freqüentado uma escola regular, apenas atendimentos na Apae. O aluno foi acolhido, apresentando algumas dificuldades de adaptação superadas com o tempo, segundo o relato da diretora.

A diretora M. era proveniente da educação infantil, sem experiência anterior em direção. A vice-diretora ingressou na escola com a diretora, mantendo com esta uma boa parceria, pois já trabalhavam juntas. As queixas de indisciplina continuaram, mas em menor escala, graças a um novo tratamento da questão, focado na gestão de sala de aula. Casos de alunos com questões de comportamento e familiares mais expressivas eram discutidos com o grupo de professores, com foco na inclusão do aluno e no atendimento às suas necessidades.

A questão da retenção foi outro indicador importante. Desde o início, a diretora problematizou a questão das retenções, prática até então comum na escola, evitando seu uso como resposta pedagógica às necessidades dos alunos. Foram formados grupos de estudo de alunos como estratégia de investimento intenso na aprendizagem. Outro indício importante de uma postura democrática da diretora foi a sua receptividade à implantação de uma classe de aceleração 
na escola, formada por uma turma de alunos adolescentes entre 14 e 16 anos, alguns provenientes de classes especiais.

Em relação à documentação escolar, foram analisados os projetos pedagógicos da escola, dos anos 2003 a 2005, quanto às referências aos temas educação inclusiva e gestão democrática. Foi realizada uma leitura dos projetos, buscando-se apreender os indícios e referências à participação democrática dos diversos atores escolares bem como alusões a itens como acesso e participação da comunidade e preocupação com a acessibilidade arquitetônica e curricular.

No projeto pedagógico de 2003, sob a administração da diretora do Estado, não se encontra menção ao atendimento a alunos com necessidades educacionais especiais ou à previsão de algum apoio específico para alunos com deficiência. Também não há referência à acessibilidade física do prédio escolar. A ausência de menção às questões da acessibilidade arquitetônica do prédio e a omissão de algum tipo de projeto específico para acompanhamento aos alunos com deficiência podem sugerir uma prática alheia às necessidades desses alunos ou ainda uma baixa intencionalidade de sistematizar as práticas existentes através do registro no projeto pedagógico. As metas propostas para o ano 2003 referem-se apenas a questões de trabalho do professor, sem alusão ao trabalho coletivo ou ao papel da gestão e de outros funcionários nas problemáticas apontadas. A ponderação acerca da ausência de cumprimento de metas como melhoria da disciplina discente, redução da reprovação, evasão e absenteísmo do professor são mencionadas na avaliação da proposta pedagógica e do plano de gestão. Também não foram observadas referências a decisões coletivas do grupo de professores ou análises mais aprofundadas e críticas das situações vivenciadas pelos educadores. Se tais análises foram feitas, não foram registradas no projeto pedagógico, o que reforça a inconsistência desse documento. Pode-se inferir, por esses dados, a existência de uma visão mais conservadora de escola, com pouca participação dos educadores em propostas coletivas.

No projeto pedagógico de 2004, sob a administração da primeira diretora não efetiva do Município, o documento adota uma orientação mais democrática, pois são propostos objetivos relacionados a um melhor conhecimento e atendimento aos pais e comunidade, também perceptível nos objetivos relativos a professores e alunos, formação permanente, valorização docente e estímulo à participação discente nas decisões da escola. A educação inclusiva comparece como uma ação a ser desenvolvida para melhoria da qualidade de ensino.

O projeto pedagógico de 2005 é feito sob a administração de M., a diretora efetiva do Município pesquisada. Já no início do documento, na caracterização da escola, são apontadas a pouca acessibilidade do prédio e a necessidade de reestruturação e reforma. Ao caracterizar a comunidade, revela preocupação em estabelecer uma relação mais empática com ela e em valorizar as características dos alunos. Nos objetivos da escola, aponta-se a importância da superação de questões como indisciplina, alto índice de alunos não-alfabéticos, repetência e descrédito da comunidade. Visa-se a uma escola democrática, organizada, de qualidade, aberta à comunidade e com melhores indicadores de alfabetização e aprovação. Para tanto, são propostas, entre outras ações, a democratização de decisões, o acolhimento da comunidade, a participação dos pais e a formação e a reflexão da prática. $\mathrm{O}$ atendimento à diversidade é destacado como meta pedagógica. Os planos de ação das professoras de sala de recursos das áreas de deficiência mental e deficiência auditiva que atuam na escola aparecem anexados ao documento, bem como o plano do 
apoio pedagógico. Projetos e atividades seqüenciadas com gêneros literários para os dois ciclos e integrados com a educação de jovens e adultos também constam do documento. Mencionam-se ainda a aplicação das verbas recebidas e o papel do conselho da escola.

De modo geral, a mudança de orientação iniciada na administração municipal é reforçada, apresentando-se mais organizada e completa. Assim, fortalece-se a hipótese inicial da importância de um diretor comprometido com a democratização escolar e com a educação inclusiva, manifestada no plano pedagógico da escola.

\section{A entrevista}

Optou-se pela realização de uma entrevista semi-estruturada, visto que a coleta de dados na linguagem do próprio sujeito permite ao investigador captar como este interpreta o mundo (Bogdan \& Biklen, 1994), no caso, as concepções sobre a educação inclusiva e a gestão democrática de escola. Foi utilizada a análise de conteúdo de Bardin (2002) para levantar e discutir as principais categorias identificadas. Essa autora propõe que se faça uma "leitura flutuante" do texto, um conceito similar ao de atenção flutuante na psicanálise, de forma a possibilitar a emergência dos temas para análise. Cabe aqui destacar a definição de tema e de análise temática para Bardin, segundo a qual

tema é a unidade de significação que se liberta naturalmente de um texto analisado segundo certos critérios relativos à teoria que serve de guia à leitura... Fazer uma análise temática consiste em descobrir os 'núcleos de sentido' que compõem a comunicação e cuja presença, ou freqüência de aparição, podem significar alguma coisa para o objetivo analítico escolhido. (p. 105)

A partir da leitura da entrevista, foram levantados alguns temas, entre os quais buscou-se uma unidade de significado que pudesse ser destacada e então relacionada com os focos de análise propostos.

Foi feito um roteiro de entrevista abrangendo os seguintes itens: 1) objetivo da pesquisa, história profissional em educação; 2) experiência com necessidades educacionais especiais; 3) expectativas sobre a escola no ingresso; 4) prioridades de trabalho; 5) critérios de atribuição de classes, inclusive de alunos com necessidades educacionais especiais; 6) experiências consideradas ilustrativas e 7) gestão da escola em termos de interação com os diversos órgãos colegiados (conselho de escola e APM). Na ocasião da entrevista, também foi acertado com a diretora que seriam feitas posteriores revisões conjuntas da transcrição da entrevista, o que resultou em ajustamentos da linguagem na transcrição.

\section{Resultados e discussão}

A análise buscou estabelecer no material coletado a existência de relações entre concepção de educação inclusiva e gestão democrática. Quando pertinente, esses dados foram analisados em conjunto com os obtidos na pesquisa documental efetuada sobre os projetos pedagógicos escolares.

A trajetória profissional em educação da diretora atendeu considerações de ordem econômica, com início profissional precoce, sempre como professora em sala de aula. Após o magistério, ingressou na faculdade de Pedagogia e continuou lecionando em escola estadual, destacando a preferência pelo trabalho com alfabetização. O concurso para diretora levou-a à decisão, considerada difícil por ela, de abandonar a sala de aula. Os motivos para a escolha desta escola atenderam a fatores pessoais e profissionais, como a proximidade da residência.

No tocante às expectativas em relação à escola, as primeiras impressões foram a de uma escola rotulada, e as dificuldades relatadas formaram 
um quadro amedrontador: "Um dia eu vim aqui conhecer a escola e elas estavam em conselho... a direção estava com muitos problemas... vou sair daqui e o primeiro concurso de professor que tiver... (risos)".

M. refletiu sobre as dificuldades, e elaborou uma estratégia de trabalho: "Bom, minha primeira ação vai ter que ser conquistar o grupo, porque se eu não tiver o grupo do meu lado, eu não vou ter nada". A relação com o grupo, como se verá, foi um dos fatores mais determinantes do seu contato positivo com a escola.

O tópico acerca da relação com a educação inclusiva na trajetória profissional talvez seja o mais importante em vista dos objetivos deste estudo. O contato inicial de M. com a diversidade ocorreu como docente. Como professora, teve sua primeira experiência com uma aluna com deficiência ao trabalhar com uma turma de primeira série, experiência pontuada de dúvidas e angústias. M. relata que o apoio ao professor oferecido pela escola ou pelo sistema educacional era insuficiente: "A concepção de inclusão estava começando... colocavam as crianças lá, sem redução de sala. Não havia uma discussão sobre a inclusão". Pode-se depreender daí a expectativa de algum tipo de orientação mais próxima, mas sem atendimento. A solidão dessa posição experimentada enquanto professora é destacada: "Foi o ano todo assim, pesquisando sozinha o que eu podia fazer por ela".

Diante da situação, M. mobilizou recursos pessoais, como a pesquisa do que propor à aluna, apelando também para a diretora da escola, lembrando a responsabilidade da instituição, e daí conseguindo encaminhamentos mais efetivos: "Até que um dia eu tive que chegar para minha diretora e falar que ela não era só minha aluna, ela era aluna da escola... Aí...é que começaram umas discussões na escola, e eu comecei a ter apoio da direção". É importante a constatação de que a aluna não era responsabilidade isolada, mas da escola como um todo, o que caracteriza uma visão de escola inclusiva, como apontado por Sage (1999). Nessa concepção de educação, os alunos devem ser considerados projetos da escola, e não fardos que acabam sendo atribuídos a professores com menor possibilidade de rejeitá-los, geralmente os ingressantes na carreira, sem prioridade na escolha. A situação de isolamento relatada pela entrevistada, testemunha e autora de transformações, aponta etapas a serem percorridas na construção de um sistema educacional inclusivo. A discussão, ao ser levada para o grupo de professores, produziu alguma mudança, ainda que incipiente. Ao avaliar o trabalho feito com a aluna, ressalta: "Quando ela começou a ter um outro olhar do grupo, ela avançou... Era respeitar o tempo dela, não adiantava deixar ela entre quatro paredes".

Na posição de diretora, a experiência docente influiu na forma como intervém junto a uma professora do aluno G., com síndrome de Down:

\footnotetext{
Da escola estar vendo ele não como uma criança diferente, mas uma criança com necessidades especiais... que às vezes ele saía mais por uma necessidade dele, mas que isso ia ser trabalhado no devido tempo com ele.... e com as crianças também, para aprender a respeitar o tempo dele.
}

A necessidade de possibilitar o acesso ao espaço da escola, deixando o aluno perceber a rotina, também é algo a ser destacado, provavelmente oriundo de sua experiência docente. Se as regras admitem flexibilização, a escola admite outras possibilidades de ação. Destaca também a importância dada ao trabalho com os outros alunos para que respeitem as diferenças. Com o tempo, o aluno G. pôde permanecer espontaneamente e por maiores períodos na sala de aula, como algo conquistado, e não simplesmente imposto. 
Quanto à aprendizagem relacionada a conteúdos escolares pelo aluno com deficiência, não é trazida como uma prioridade, mas sim, sua inserção no espaço escolar, indicando as dificuldades que as escolas têm em realizar adaptações curriculares mais efetivas. Ao falar sobre a avaliação, enfatiza a adequação de objetivos e desafios ao aluno, realizando adaptações nas atividades propostas: "A gente conversa, traça os objetivos para cada bimestre daquele aluno".

A continuidade com a mesma professora, ou com a turma no ano seguinte, também é avaliada, considerando-se as necessidades do aluno, sua maior dificuldade de adaptação a mudanças e outros fatores: "Ele (G.) continuou com a professora esse ano, porque eu sei que a adaptação é mais lenta... porque eu vou quebrar um processo, vou fazer ele se adaptar novamente". A avaliação do aluno se dá, portanto, com um olhar mais abrangente, atento à relação com o contexto escolar e com o professor.

O processo de atribuição de turmas é abordado com o grupo de professores, revelando a atuação do diretor como facilitador no processo de inclusão escolar, como preconizado por Glatter (1995), Sage (1999) e Mantoan (2001). Busca-se a liberdade de escolha, que deve resultar de um investimento formativo por parte da equipe gestora junto aos professores. Mais uma vez, a experiência como professora serve de referencial para M. na avaliação da continuidade de um aluno com um professor em outro ano: "Eu sei por mim... para o professor também é desgastante... a gente avalia se elas estavam dispostas a continuar... porque quando tem um querer, eu acho assim, o professor tem que abraçar a causa".

A preocupação com a qualidade do trabalho do professor e, portanto, com a do processo de aprendizagem do aluno, está presente nessa orientação. Também é reiterado o suporte ao trabalho do professor, como uma forma de tranqüilizá-lo quanto às necessidades que surjam no seu trabalho com o aluno. Ao ser questionada quanto ao papel da diretora diante da recusa de professor ao trabalho, reflete:

Aí o papel da gestão é fundamental. Como a gente já sabia que vinham esses alunos com antecedência, a gente foi conversando e discutindo no horário de trabalho pedagógico coletivo (HTPC) sobre essas crianças... mostrando pro professor que ele é capaz, que eles vão ter o suporte... se já coloca esse aluno com deficiência como um estereótipo, como uma carga, aí é claro que o grupo todo... Qual é o seu olhar para esse aluno? Eu acho que isso é importante também.

A gestão através de exemplos concretos é uma forma importante de persuasão dos professores (Glatter, 1995), como evidenciado acima. A concepção do diretor acerca da educação inclusiva, portanto, poderá influenciar a equipe (Sage, 1999), pois ele/ ela está atuando como formador desse grupo (Barros, 2004). A prática de conversar abertamente sobre os desafios trazidos pelo trabalho com a inclusão escolar mostra uma preocupação em transpor a imagem idealizada da escola, e discutir com o grupo as questões reais propicia transformações efetivas (Sekkel, 2003). A responsabilidade pelos encaminhamentos relativos a cada aluno é assumida coletivamente, indicando uma forma democrática de gerir as relações do espaço escolar (Libâneo, 2001).

No que se refere à relação com o sistema educacional, a influência do sistema escolar e suas orientações aparecem em diferentes situações que merecem ser exploradas. Como apontado no início da entrevista, as limitações impostas pelo sistema foram sentidas já na experiência como professora de uma aluna com necessidades educacionais especiais, pela falta de uma orientação adequada, de acompanhamento e de formação, aliada à falta de espaços escolares adequados e a medidas como redução do número de alunos em sala. Como diretora, as limitações 
consistem na falta de uma orientação mais sistemática do sistema municipal que respalde as ações escolares:

Os objetivos são diferentes, se eu for cobrar dele alfabetização, ele não vai sair da primeira série. É como se brecasse o nosso trabalho, tira o nosso chão. Você sabe que é um direito da criança estar aqui, mas, em algumas ações que você tem, é questionada o tempo todo.

Pode-se inferir a partir do relato que, ainda que a educação inclusiva seja hoje uma realidade inquestionável, os sistemas têm feito pouco no sentido de adotar medidas concretas para sua efetiva implantação e apoiar claramente as transformações que a escola se empenha em realizar (Sage, 1999).

Quanto ao envolvimento da comunidade e dos pais como estratégia da gestão democrática, uma outra dificuldade trazida pela diretora é a aproximação inicial da comunidade com a escola, em função da postura resistente dos pais:

Os pais chegavam com duas pedras na mão. Então a gente gastava 30 minutos... para tirar as pedras das mãos dos pais... Eles tinham muita resistência, porque achavam que a gente ia humilhar o filho deles... Aqueles pais com filhos com maiores dificuldades foram chamados um a um, e, feito esse trabalho, que começava a surtir algum efeito na terceira, na quarta conversa, não era assim na primeira conversa.

Pode-se pensar que a resistência apresentada pelos pais ao chamado da escola pode tanto se basear em suas experiências pessoais como alunos como também em situações mais recentes, como pais. A prática de algumas escolas de convocar os pais para criticá-los e apontar as suas falhas é, infelizmente, bastante comum. A reformulação da reunião com pais é colocada como uma forma de alcançar maior proximidade com a escola: "A professora começou a falar do trabalho dela, das suas dificuldades em sala... do que ela precisava, então a reunião passou a ser mais formativa. E, numa sala que tem inclusão, $O$ professor trabalha isso com todos os pais".

Uma conquista importante envolve levar o trabalho inclusivo da escola para a pauta da reunião com pais (Tezani, 2004), mostrando preocupação em envolver a comunidade com a questão. Também foi comentado pela diretora o trabalho junto aos pais de alunos sobre a importância em orientar seus filhos para acolher os colegas sem preconceitos: "É importante a professora trabalhar isso na reunião de pais, até para os pais trabalharem com o filho aquela questão do não rótulo, 'ah, ele não sabe nada'".

Sobre o funcionamento dos órgãos colegiados, como o conselho de escola e a APM, a diretora relata que a equipe gestora realizou um trabalho sistemático, no sentido de ampliar a participação dos pais, uma vez que os órgãos colegiados tinham até então um caráter meramente burocrático:

Nós queríamos a comunidade na escola, mas não apenas nos eventos. Os pais viram as produções das crianças, nós tivemos muitos elogios. E eu senti que, a partir dessa exposição, dessa feira que teve aqui na escola, a comunidade começou a chegar.

Ao utilizar seu trabalho pedagógico com os alunos como estímulo à participação da comunidade, a escola reafirma seu papel, e possibilita que os pais se reafirmem no seu. Outra avaliação positiva é feita pela diretora em relação às reivindicações expressas pelos pais, como, por exemplo, o pedido de estagiária para apoio à inclusão, mesmo para os que não têm filhos com necessidades educacionais especiais:

Eles não estão pensando só nos aspectos quantitativos, como material, porque antigamente a APM só reivindicava isso; eles estão reivindicando aspectos qualitativos. Quando se fala na estagiária de inclusão, ele sabe que vai ser um benefício para a criança e para o filho dele, porque a professora vai conseguir se articular melhor. 
Assim, avalia-se que a participação da comunidade na escola tenha sido ampliada, não só do ponto de vista quantitativo mas também da qualidade das reivindicações apresentadas.

A recorrência a uma estratégia grupal coletiva é um tema recursivo e norteador no relato da diretora. Está presente quando conta sua primeira experiência de trabalho com uma aluna com necessidades educacionais especiais, o que a levou a buscar apoio no coletivo escolar. É retomado quando expõe seu objetivo principal ao ingressar na escola estudada, de conquistar o grupo de professores. Buscar a participação dos pais e definir ações pedagógicas com o corpo docente são outros exemplos que podem ser lembrados. O recurso ao grupo como estratégia recorrente de atuação indica uma forma de democratizar decisões de trabalho, propiciando uma participação mais ativa dos envolvidos e dividindo o peso da responsabilidade entre todos (Araújo, 2002). Uma forma de gestão democrática poderá ser sentida em todos os campos da atividade escolar, como o administrativo, o organizacional, etc.

As relações pedagógicas, na implantação de uma cultura escolar inclusiva, são concretizadas na divisão de responsabilidades com o corpo docente, não localizando a decisão em um professor isoladamente ou na equipe gestora, como no caso da atribuição dos alunos com necessidades educacionais especiais para os que voluntariamente se dispunham a fazer esse trabalho. Outra indicação dessa orientação para o trabalho coletivo é a solicitação aos pais de orientarem os filhos a aceitar seus colegas independentemente das diferenças. A ação indica uma preocupação em agir em vários campos que permeiam o acolhimento e o pertencimento do aluno à escola, contando para isso com a intervenção de todos os envolvidos no trabalho escolar (Sage, 1999).
De acordo com os focos propostos para a análise, a cultura escolar atual percebida no discurso da diretora é a de uma escola que busca a ação coletiva como uma forma de operar nas diferentes esferas de atuação, seja pedagógica, seja administrativa, seja das relações com a comunidade. As necessidades individuais dos alunos e dos pais são consideradas, e a postura da escola é a de compreender seus motivos, em vez de acusá-los, fazer cobranças ou lamentar-se.

Pode-se dizer que essa determinada cultura escolar é inclusiva, e busca o pertencimento dos alunos à escola. Assim, é bastante positivo o fato de a diretora não considerar a alternativa da escola especial para o encaminhamento, como no caso do aluno com síndrome de Down, relatando maior preocupação inicial com a sua relação com o espaço escolar, e não com sua aprendizagem. Se é fato que a aprendizagem será sempre privilegiada ao avaliar os benefícios que um aluno tem com a inclusão escolar, também é fato que isso poderia resultar em uma forma de exclusão, com considerações do tipo: o que este aluno está fazendo aqui, se "não aprende" como os outros? Essa questão é talvez uma das mais complexas nos debates sobre educação inclusiva: a aprendizagem de alunos com necessidades educacionais especiais. É possível que a resposta se encontre nos contextos de aprendizagem oferecidos, sendo a problematização da proposta curricular da escola uma importante via de acesso a essa reflexão. Nesse cenário, a capacidade de tolerar o não-saber, de assumir uma postura investigativa, buscando coletivamente algumas respostas, é fundamental para atacar as primeiras resistências ao recebimento do aluno e promover o acolhimento às diferenças significativas - o que, se é ainda incipiente em relação ao tamanho da tarefa, é, sem dúvida, um começo imprescindível. Portanto, dentro de uma cultura escolar sujeita a práticas e a currículos tradicionais, ver o aluno que não aprende da mesma forma que os outros como um desafio que é de competência da 
escola produz uma pequena e bem-vinda transformação nessa cultura.

Quanto aos aspectos pessoais da diretora em relação à cultura escolar, é possível lembrar alguns pontos destacados pela literatura, como a busca pelo trabalho coletivo, marcante em sua trajetória profissional em diversas ações como diretora, fator importante na gestão escolar favorecedora do diálogo (Nogueira, 1993) e da descentralização de decisões (Araújo, 2002). Outro ponto que merece destaque é a forma como a diretora, mesmo iniciante, se aproximou do grupo de professores:

O grupo também estava ansioso, porque era uma pessoa que eles nem sabiam, não era uma diretora, era uma pessoa, que ninguém nunca ouviu falar... Aí eu cheguei, conquistando o grupo. Fui muito aberta para o grupo, falei: "gente, eu não sei trabalhar com fundamental, minha experiência com fundamental é em outra rede, mas estou aqui para a gente construir junto a nossa história.

Ao chegar como uma pessoa, e não como uma diretora, demonstra disposição em estabelecer um vínculo horizontal com o grupo. Pode assim desarmar as defesas iniciais, e compor com o grupo um coletivo. É claro que essa intenção perde todo o sentido se ficar apenas enunciada, devendo ser praticada, como, por exemplo, na atribuição dos alunos com necessidades educacionais especiais junto com os professores. Outra questão que pode ser relacionada com a sua primeira experiência como diretora é seu pensar como professora, dando destaque à preocupação com a aprendizagem, como visto num trecho da entrevista:

Quando me chamaram, fiquei muito em dúvida, porque eu amo a sala de aula e o contato com as crianças, tanto que hoje, na escola, uma coisa que eu prezo muito é a parte pedagógica, eu não consigo me desligar da parte pedagógica.

A contradição apontada por Paro (2002) e Saviani (2000) entre o diretor-educador e o diretor-administrador é concretamente vivida quando resulta no distanciamento desse profissional da parte pedagógica. Ter como principal preocupação a parte pedagógica da escola é algo esperado do diretor; sabe-se, contudo, que muitos diretores são "tragados" pelas questões administrativas da escola (Romão \& Padilha, 2001). Já outros fazem essa opção de forma consciente, deixando a parte pedagógica a cargo do coordenador pedagógico. No caso dessa diretora, assim como no da diretora anterior (também funcionária do Município), as questões administrativas são colocadas de modo secundário às pedagógicas, indicando uma concepção de aprendizagem mais voltada para a função da escola como educadora, como apontado por Saviani (2000). Para os diretores assim posicionados, a luta contra a burocracia da instituição escolar é uma constante, pois o sistema educacional tem suas demandas burocráticas sempre atualizadas (Lyra, 2003; Reis, 2000), o que exige dos profissionais uma afinação renovada de sua postura como educadores.

A experiência como professora também motivou a diretora a ter uma atitude empática com as dificuldades encontradas pelos professores de alunos com necessidades educacionais especiais: "Eu sei... pela experiência que tive, eu tive uma aluna de inclusão: para o professor também é desgastante". Proporcionar boas condições de trabalho ao professor pela possibilidade de debater com o grupo as dificuldades, e encontrar nessa discussão boas formas de intervenção, é um objetivo da diretora, relacionado com sua experiência profissional.

Esses e outros exemplos podem ser utilizados para refletir sobre a importância da trajetória profissional, das concepções educacionais e da experiência pessoal na educação inclusiva e na gestão democrática do ensino na cultura escolar. Como anteriormente discutido, o diretor é parte de um contexto mais amplo, e tem sua ação subordinada a 
vários fatores, como as orientações legais do sistema. Contudo, ele pode intervir na sua efetivação, pode submeter-se ou lutar pelo que acredita, como se observa na queixa de falta de orientação e apoio do sistema em relação às diretrizes de avaliação. Assim, parece haver um espaço onde é possível agir dentro de um sistema mais ou menos rígido, espaço esse proporcional às concepções do diretor enquanto educador, e como ele as traduz em ações.

Finalmente, ao avaliar se é possível estabelecer, a partir da entrevista analisada, relações entre a concepção de educação inclusiva e a gestão democrática, a resposta é afirmativa, uma vez que, neste estudo de caso, a atuação da diretora se dá de forma a democratizar decisões, e isso se desdobra nos encaminhamentos relativos aos alunos com necessidades educacionais especiais, como quando procura atuar com os professores por meio da argumentação, em lugar da imposição de decisões tomadas de forma centralizada, ou no trabalho com os pais para debater a inclusão escolar.

\section{Considerações finais}

A principal articulação deste trabalho com a Psicologia histórico-cultural de Vigotski é a reflexão sobre os diferentes aspectos do contexto escolar, sejam humanos, administrativos ou pedagógicos, como fatores constitucionais importantes da cultura escolar, e desta como influência decisiva para a formação tanto dos profissionais da educação ali alocados quanto de seu público-alvo: todos os alunos, incluindo aí tanto aqueles que tenham quanto os que não tenham deficiências. Foram apresentadas algumas idéias de Vigotski, de modo resumido, para enfatizar alguns conceitos por ele explorados em relação ao papel fundamental do contexto social no desenvolvimento da criança com deficiência e, portanto, para ressaltar a importância da escolarização para essas crianças bem como para justificar a investigação da escola como uma cultura que atua na mediação entre a criança com deficiência e a sociedade na qual essa escola se insere. Partindo dos pressupostos defendidos por esse autor, pode-se afirmar que uma cultura educacional inclusiva contribuirá para melhor atendimento e melhor formação dos alunos.

Neste trabalho, a democratização da gestão e a educação inclusiva mostraramse estreitamente relacionadas, confirmando a proposição inicial de que, quanto mais democrática for a escola, mais inclusiva será, pois a sua real abertura para todos implica a democratização do ensino. Se a escola é para todos, certamente deverá abarcar, no processo de escolarização, os alunos com necessidades educacionais especiais, seja qual for a sua origem. Assim, uma cultura escolar inclusiva será mais efetivamente implantada se as relações escolares forem permeadas pelo respeito ao outro e por uma postura democrática da gestão escolar.

Não se deve equivocadamente concluir que é preciso buscar indivíduos com características pessoais democráticas para ocupar funções importantes, como a direção, para efetivar a cultura escolar inclusiva. Deve-se, mais apropriadamente, investir na produção de contextos escolares que favoreçam a construção de práticas democráticas, para que os professores e alunos as vivenciem de forma concreta. O diretor de amanhã é o professor de hoje e o aluno de ontem, cujas experiências de participação em uma sociedade democrática são importantes para a consolidação de suas concepções de educação e de relações humanas em geral.

Os sistemas educacionais também devem assumir sua parte de responsabilidade, investindo na construção de contextos escolares democráticos, seja através da formação continuada de seus profissionais, seja através da mensagem subliminar que passam por meio de políticas públicas: 
um sistema não pode se autoproclamar inclusivo mantendo condições desfavoráveis para a efetiva inclusão de alunos com necessidades educacionais especiais, como classes numerosas, currículos excludentes ou prédios sem acessibilidade. Ao examinar a documentação do Município que aborda a questão da educação inclusiva, pôde-se observar a crescente referência à importância desse tipo de educação. Se esse é um indício importante para concluir que há uma preocupação governamental com a questão, a preocupação apenas não deve ser tomada como suficiente, uma vez que, entre a enunciação formal de intenções e a mudança efetiva de práticas, se observa grande distanciamento. A prática analisada neste trabalho, contudo, afina-se com os princípios democráticos enunciados nos documentos oficiais que, em contrapartida, podem respaldá-la, propiciando um ambiente mais favorável a diretores afinados com uma proposta educacional inclusiva.

Claudia Lopes da Silva

Instituto de Psicologia da Universidade de São Paulo; doutoranda em Educação na Faculdade de Educação da Universidade de São Paulo (FE-USP).

E-mail: claulop@usp.br

\section{Maria Isabel da Silva Leme}

Professora associada do Instituto de Psicologia da Universidade de São Paulo (IP-USP).

E-mail: belleme@usp.br

Endereço para envio de correspondência:

Avenida Professor Mello Moraes, 1721 - Bloco A - São Paulo - SP - Brasil, CEP: 05508-900 


\section{Referências}

Almeida, J. G. (2003). A intervenção (im)possível no cotidiano de uma escola: relato do trajeto de um diretor de escola na rede pública municipal. Tese de Doutorado, Faculdade de Educação, Universidade de São Paulo, São Paulo.

Araújo, U. F. (2002). A construção de escolas democráticas. São Paulo: Moderna.

Bardin, L. (2002). Análise de conteúdo. Lisboa: Edições 70.

Barros, C. O. T. (2004). O papel do diretor escolar na formação em serviço: um estudo da proposta de formação da Secretaria Municipal de Educação de São Bernardo do Campo. Dissertação de Mestrado, Faculdade de Educação, Universidade de São Paulo, São Paulo.

Bogdan, R., \& Biklen, S. (1994). Investigação qualitativa em educação. Porto, Portugal: Porto Editorial.

Brandão, C. R. (1983). O que é educação (10a ed.). São Paulo: Brasiliense.

Duarte, N. (2001). Vigotski e o aprender a aprender (2a ed.). Campinas, SP: Autores Associados.

Evans, P. (1995). Algumas implicações da obra de Vigotski na educação especial. In H. Daniels (Org.), Vigotski em foco: pressupostos e desdobramentos (2a ed.). Campinas, SP: Papirus.

Frigoto, G. (1997). Introdução. In M. Gadotti, M., \& J. Romão (Orgs.), Autonomia da escola: princípios e propostas (2a ed.). São Paulo: Cortez.

Glatter, R. (1995). A gestão como meio de inovação e mudança nas escolas. In A. Nóvoa (Org.), As organizações escolares em análise (2a ed.). Lisboa: Dom Quixote.

Libâneo, J. C. (2001). Organização e gestão da escola: teoria e prática. Goiânia: Alternativa.

Lima, E. C. A. S. (1993). A escola e seu diretor: algumas reflexões. In $O$ papel do diretor e a escola de $1^{\circ}$ grau (pp. 117-124, Série Idéias, 12). São Paulo: FDE.

Lyra, Z. A. (2003). A gestão e o gestor da educação do Estado de São Paulo: um estudo de caso sobre a conformação após 1995. Dissertação de Mestrado, Faculdade de Educação, Universidade Estadual de Campinas, Campinas, SP.

Mantoan, M. T. E. (2001). Abrindo a escola às diferenças. In M. T. E. Mantoan (Org.), Pensando e fazendo educação de qualidade (Cap. 5). São Paulo: Moderna.

Miranda, M. G. (2004). O processo de socialização na escola: a evolução da condição social da criança. In S. T. M. Lane \& W. Codo (Orgs.), Psicologia social: o homem em movimento (13a ed.). São Paulo: Brasiliense.

Nogueira, M. J. (1993). Diretor dirigente: a construção de um projeto pedagógico na escola pública. In O papel do diretor e a escola de $1^{\circ}$ grau (Série Idéias, 15). São Paulo: FDE.

Nóvoa, A. (1995). Para uma análise das instituições escolares. In A. Nóvoa (Org.), As organizações escolares em análise (2a ed.). Lisboa: Dom Quixote.

Omote, S. (1994). Deficiência e não-deficiência: recortes de um mesmo tecido. Revista Brasileira de Educação Especial, 1(2), 65-73.

Paro, V. H. (2002). Administração escolar: introdução crítica (11a ed.). São Paulo: Cortez.

Paro, V. H. (2001). Escritos sobre educação. São Paulo: Xamã.

Pérez Gómez, A. I. (1998). A aprendizagem escolar: da didática operatória à reconstrução da cultura na sala de aula. In J.
G. Sacristán \& A. I. Pérez Gómez (Org.), Compreender e transformar o ensino (4a ed.). Porto Alegre: ArtMed.

Prieto, R. G. (2002). Políticas públicas de inclusão: compromissos do poder público, da escola e dos professores. Recuperado em 19 de julho de 2005, de http://www.educacaoonline.pro. br/art_politicas_publicas_de_inclusao.asp

Rego, T. C. (2002). Configurações sociais e singularidades: o impacto da escola na constituição dos sujeitos. In M. K. Oliveira, D. T. R. Souza \& T. C. Rego (Orgs.), Psicologia, educação e as temáticas da vida contemporânea. São Paulo: Moderna.

Reis, M. G. F. A. (2000). O compromisso político-social do diretor como educador. Dissertação de Mestrado, Universidade Federal de São Carlos, São Carlos, SP.

Romão, J. E., \& Padilha, P. R. (2001). Diretores escolares e a gestão democrática da escola. In M. Gadotti \& J. E. Romão (Orgs.), Autonomia da escola: princípios e propostas (4a ed.). São Paulo: Cortez.

Sage, D. D. (1999). Estratégias administrativas para a realização do ensino inclusivo. In S. Stainback \& W. Stainback, Inclusão: um guia para educadores. Porto Alegre: Artes Médicas Sul.

Sant'Ana, I. M. (2004). Educação inclusiva: concepções de professores e diretores. In G. P. Witter (Org.), Psicologia e educação: professor, ensino e aprendizagem. Campinas, SP: Alínea.

Saviani, D. (2000). Papel do diretor de escola numa sociedade em crise. In D. Saviani, Educação: do senso comum à consciência filosófica (13a ed.). Campinas, SP: Autores Associados.

Schirmer, C. R., Browning, N., Bersch, R., \& Machado, R. (2007). Formação continuada a distância de professores para $o$ atendimento educacional especializado: deficiência física. Brasília, DF: SEESP/SEED/MEC.

Sekkel, M. C. (2003). A construção de um ambiente inclusivo na educação infantil: relato e reflexão sobre uma experiência. Tese de Doutorado, Instituto de Psicologia, Universidade de São Paulo, São Paulo.

Stake, R. E. (2000). Case studies. In N. K. Denzin \& Y. S. Lincoln, Handbook of qualitative research (2nd ed.). London: Thousand Oaks.

Silva Jr., J. R., \& Ferretti, C. J. (2004). O institucional, a organização e a cultura da escola. São Paulo: Xamã.

Tezani, T. C. R. (2004). Caminhos para a construção da escola inclusiva: a relação entre a gestão escolar e o processo de inclusão. Dissertação de Mestrado, Universidade Federal de São Carlos, São Carlos, SP.

UNESCO. (1994). Declaração de Salamanca e enquadramento da acção na área das necessidades educativas especiais. Conferência Mundial Sobre Necessidades Educativas Especiais: Acesso e Qualidade. Salamanca, Espanha: Organização das Nações Unidas para a Educação, a Ciência e a Cultura/Ministério da Educação e Ciência de Espanha.

Vale, J. M. F. (1995). Administração educacional e escolar. In A autonomia e a qualidade do ensino na escola pública (Série Idéias, 16). São Paulo: FDE.

Vigotski, L. S. (2003). Psicologia pedagógica. Porto Alegre: ArtMed.

Vigotski, L. S. (1997). Los problemas fundamentales de la defefectología contemporánea. In L. S. Vigotski, Obras escogidas. Vol. 5: Fundamentos de defectología. Madrid: Visor. (Trabalho original publicado em 1929)

Vigotski, L. S. (1997). Acerca de los procesos compensatorios em el desarollo del nino mentalmente retrasado. In L. S. Vigotski, Obras escogidas. Vol. 5: Fundamentos de defectología. Madrid: Visor. (Trabalho original publicado em 1931) 